\section{Case Reports in Dermatology}

\title{
Reactive Eccrine Syringofibroadenoma Associated with Neuropathy, Venous Stasis, and Diabetic Foot Ulcer
}

\author{
Thirawut Sirikham Salinee Rojhirunsakool Vasanop Vachiramon \\ Division of Dermatology, Faculty of Medicine Ramathibodi Hospital, Mahidol University, \\ Bangkok, Thailand
}

\section{Keywords}

Adnexal neoplasm - Adnexal tumor - Diabetes mellitus - Eccrine syringofibroadenoma .

Venous insufficiency

\begin{abstract}
Eccrine syringofibroadenoma (ESFA) is an uncommon benign adnexal neoplasm which derives from cells of the acrosyringium of eccrine sweat glands. The clinical appearance is nonspecific but the histological features are typical. Five clinical subtypes of ESFA exist: (1) solitary ESFA; (2) multiple ESFA associated with ectodermal dysplasia; (3) multiple ESFA without cutaneous features; (4) unilateral linear ESFA (nevoid), and (5) reactive ESFA associated with inflammatory or neoplastic dermatoses. We report the case of a 42-year-old man with longstanding diabetes and neuropathy, presenting with a 4-year history of asymptomatic erythematous plaques on a background of brown hyperpigmentation on the left foot. The clinical presentation and histopathological findings are compatible with reactive ESFA.
\end{abstract}

(c) 2016 The Author(s)

Published by S. Karger AG, Basel 


\section{Case Report}

A 42-year-old man presented with slowly progressive asymptomatic red plaques on the left foot which developed over 4 years. He was treated by topical corticosteroids with minimal improvement. He had no weight loss, prolonged fever, or night sweat. There was no family history of similar lesions. He had a 7-year history of type 2 diabetes mellitus which was treated with oral metformin and insulin injections. He had undergone amputation of the 1st, 2nd, and 3rd toe of the left foot due to neuropathic arthropathy 5 years earlier.

Physical examination revealed two discrete, well-defined, moist, macerated, erythematous, verrucous plaques on a background of diffuse red-brown discoloration on the left foot (fig. 1, fig. 2). Peripheral arterial pulses on both legs were normal and regular. There was no fever, lymphadenopathy, or hepatosplenomegaly. Other physical examinations were within normal limits. A 4-mm punch biopsy specimen was obtained from the lesion for routine histological examination.

Histopathological results showed multiple foci of thin anastomosing strands of uniform cuboidal cells emanating from the epidermis. The epithelial strands showed ductal differentiation, embedded within fibrovascular stroma (fig. 3, fig. 4). Doppler ultrasound of the left leg showed evidence of severe degree of venous reflux involving the left saphenofemoral junction and common femoral vein.

In this case, a complete excision with flap or graft was offered but the patient refused surgery. He was treated with monthly cryotherapy using liquid nitrogen spray and attended follow-ups with surveillance for malignant change. Venous stripping was performed as the treatment for severe venous reflux, which resulted in partial improvement of the lesion.

\section{Discussion}

Eccrine syringofibroadenoma (ESFA), first described by Mascaro [1] in 1963, is a rare benign adnexal neoplasm considered to originate from the excretory portion of eccrine sweat glands [2]. It typically presents in elderly patients between the 7th and 8th decade of life. The clinical manifestation of ESFA is slow-growing flesh- to reddish-colored verrucous nodules or plaques. The distribution of the lesions is most often on the extremities. Less commonly affected parts include the face, torso, buttock, nail, and peristomal skin [2, 3].

ESFA is categorized into 5 subtypes according to its clinical presentation: (1) solitary ESFA, a solitary verrucous nodule in elderly adults; (2) multiple ESFA associated with Clouston syndrome and Schöpf-Schulz-Passarge syndrome; (3) multiple ESFA without associated cutaneous findings, also referred to as syringofibroadenomatosis; (4) nonfamilial unilateral linear ESFA (nevoid ESFA), and (5) reactive ESFA associated with inflammatory or neoplastic dermatoses (e.g., erosive lichen planus, bullous pemphigoid, epidermolysis bullosa, primary cutaneous amyloidosis, burn scar, venous stasis, chronic diabetic foot ulcer, neuropathy, nevus sebaceous, and squamous cell carcinoma) [2, 4-11].

The case reported here is most likely reactive in nature, subsequent to multiple pathogenic factors including venous stasis, neuropathy, and diabetic foot ulcer, as all conditions were present at the sites of the ESFA lesions. Venous stasis was evident from the hemosiderin pigmentation on his legs. Histopathological examination and Doppler ultrasound study of the left leg also supported this finding. In addition, chronic diabetic foot ulcer would have resulted in chronic inflammation of the skin of the lower limbs, which could create the opportunity for aberrant tissue proliferation. Neuropathy may also have contributed to the 
development of ESFA in this case. The mechanism by which neuropathy may be related to the proliferation of eccrine structures was postulated by Tey et al. [8]. Postganglionic sympathetic fibers are the primary innervation of eccrine sweat glands. The production of proteins (cholinergic differentiation factors and vasoactive intestinal peptide) by the sweat glands has been shown to be induced by the innervation. The neurons have also been shown to undergo developmental differentiation to decrease the production of catecholamine as a result of a reciprocal induction by the sweat glands [12]. Aberrant functions of autonomic neurons associated with long-standing diabetes could possibly alter the process of regeneration and cellular proliferation found in the eccrine tissue after injury.

The differential diagnoses include chronic eczema, warts, chronic infections (e.g., deep fungal infection, tuberculosis, and nontuberculous mycobacterial infection), benign and malignant tumors (e.g., eccrine poroma, fibroepithelioma of Pinkus, verrucous carcinoma, and squamous cell carcinoma) $[7,8]$.

The histological features of ESFA are diagnostic. It is characterized by anastomosing strands of thin epithelial cords, surrounded by abundant fibrous tissue $[3,9]$. The epidermis shows long, thin projections, with confluent terminations similar to crab claws. The epithelial cords and strands characteristically show ductal differentiation. The tumor is usually limited to the papillary dermis. These cells may show ductal differentiation evidenced by positivity to immunohistochemical stains (e.g., CEA and BER-Ep4). The clinical course of ESFA is typically benign. Spontaneous involution has been reported in reactive ESFA [9]. Malignant transformation into syringofibrocarcinoma and eccrine porocarcinoma is possible $[13,14]$. However, the risk of occurrence is unknown. Metastatic disease has not been reported [7]. In addition, the coexistence of ESFA and squamous cell carcinoma has been described. Whether squamous cell carcinoma represents a malignant degeneration of ESFA or ESFA develops in response to squamous cell carcinoma is unclear [7].

The treatment of ESFA depends on the number, location, and resectability of the lesions. Solitary ESFA is treated by surgical excision. In unresectable cases, monitoring and generous sampling to rule out malignant transformation are recommended $[3,9]$. Other treatment options include cryotherapy, curettage, electrodessication, ablative laser therapy, photodynamic therapy, radiotherapy, 5 -fluorouracil, imiquimod, and topical and systemic retinoids with variable outcomes $[2,8,15]$.

\section{Statement of Ethics}

The patient gave written informed consent.

\section{Disclosure Statement}

The authors declare no conflicts of interest.

\section{References}

1 Mascaro JM: Considerations on fibro-epithelial tumors: exocrine syringofibradenoma (in French). Ann Dermatol Syphiligr 1963;90:143-53.

-2 Bottino CB, Guimaraes TF, Gomes FR, D’Acri AM, Lima RB, Martins CJ: Solitary eccrine syringofibroadenoma - case report. An Bras Dermatol 2015;90(suppl 1):235-238. 
Sirikham et al:: Reactive Eccrine Syringofibroadenoma Associated with Neuropathy, Venous Stasis, and Diabetic Foot Ulcer

3 Mattoch IW, Pham N, Robbins JB, Bogomilsky J, Tandon M, Kohler S: Reactive eccrine syringofibroadenoma arising in peristomal skin: an unusual presentation of a rare lesion. J Am Acad Dermatol 2008;58:691-696.

-4 Andrade AC, Vieira DC, Harris OM, Pithon MM: Clouston syndrome associated with eccrine syringofibroadenoma. An Bras Dermatol 2014;89:504-506.

5 Hampton PJ, Angus B, Carmichael AJ: A case of Schöpf-Schulz-Passarge syndrome. Clin Exp Dermatol 2005;30:528-530.

6 Saggini A, Mully T: Reactive eccrine syringofibroadenomatosis secondary to primary cutaneous amyloidosis: a novel association. J Cutan Pathol 2014;41:380-385.

7 Schadt CR, Boyd AS: Eccrine syringofibroadenoma with coexistent squamous cell carcinoma. J Cutan Pathol 2007;34(suppl 1):71-74.

-8 Tey HL, Chong WS, Wong SN: Leprosy-associated eccrine syringofibroadenoma of Mascaro. Clin Exp Dermatol 2007;32:533-535.

-9 Tey HL: Characterizing the nature of eccrine syringofibroadenoma: illustration with a case showing spontaneous involution. Clin Exp Dermatol 2009;34:e66-e68.

10 Tey HL, Tan SH: Reactive eccrine syringofibroadenomatosis associated with venous stasis and plaque psoriasis. Acta Derm Venereol 2008;88:82-84.

11 Billson VR, Dyall-Smith DJ: Eccrine syringofibroadenoma: a report of 2 cases. Pathology 1991;23:259262.

12 Habecker BA, Tresser SJ, Rao MS, Landis SC: Production of sweat gland cholinergic differentiation factor depends on innervation. Dev Biol 1995;167:307-316.

13 Katane M, Akiyama M, Ohnishi T, Watanabe S, Matsuo I: Carcinomatous transformation of eccrine syringofibroadenoma. J Cutan Pathol 2003;30:211-214.

14 Bjarke T, Ternesten-Bratel A, Hedblad M, Rausing A: Carcinoma and eccrine syringofibroadenoma: a report of five cases. J Cutan Pathol 2003;30:382-392.

15 Husein-ElAhmed H, Caba-Molina M, Naranjo-Sintes R, Aneiros-Cachaza J: Solitary eccrine syringofibroadenoma arising on the toe. J Dtsch Dermatol Ges 2014;12:148-150.

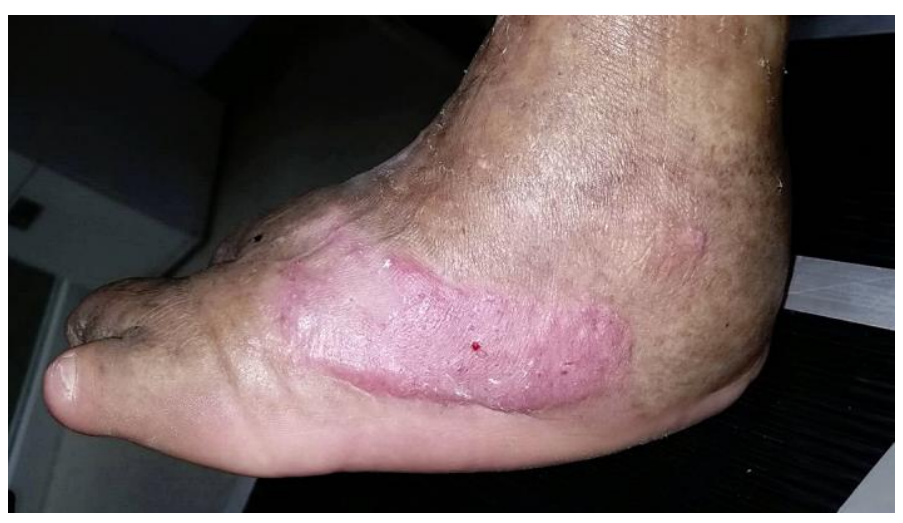

Fig. 1. Well-defined, moist, macerated, erythematous, verrucous plaques on a background of diffuse redbrown discoloration on the left foot. 


\section{Case Reports in \\ Dermatology}

Case Rep Dermatol 2016;8:124-129

Sirikham et al:: Reactive Eccrine Syringofibroadenoma Associated with Neuropathy, Venous Stasis, and Diabetic Foot Ulcer

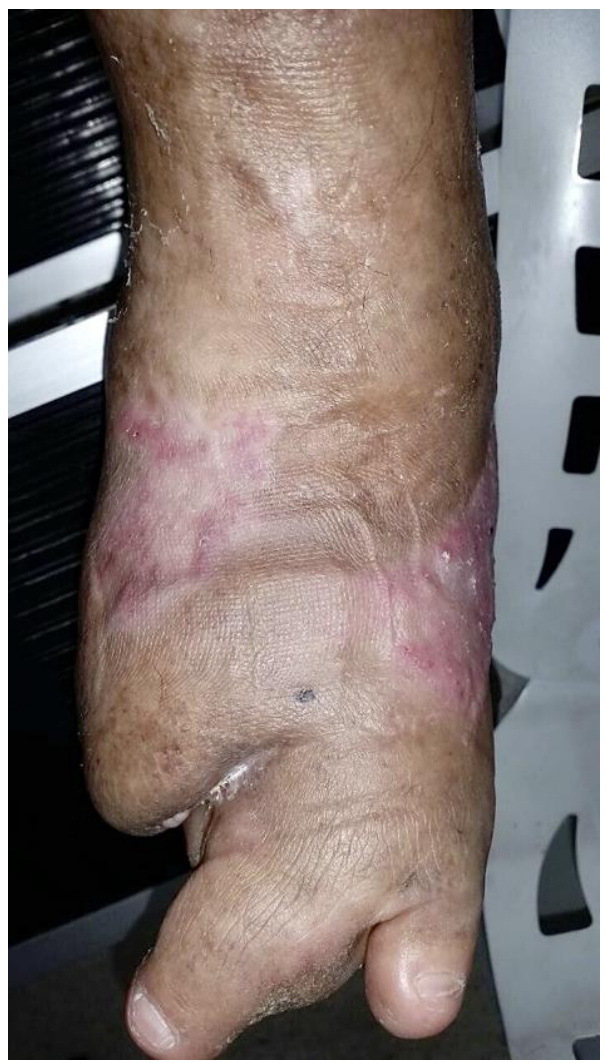

Fig. 2. Two discrete, well-defined, moist, macerated, erythematous, verrucous plaques on a background of venous stasis on the left foot.

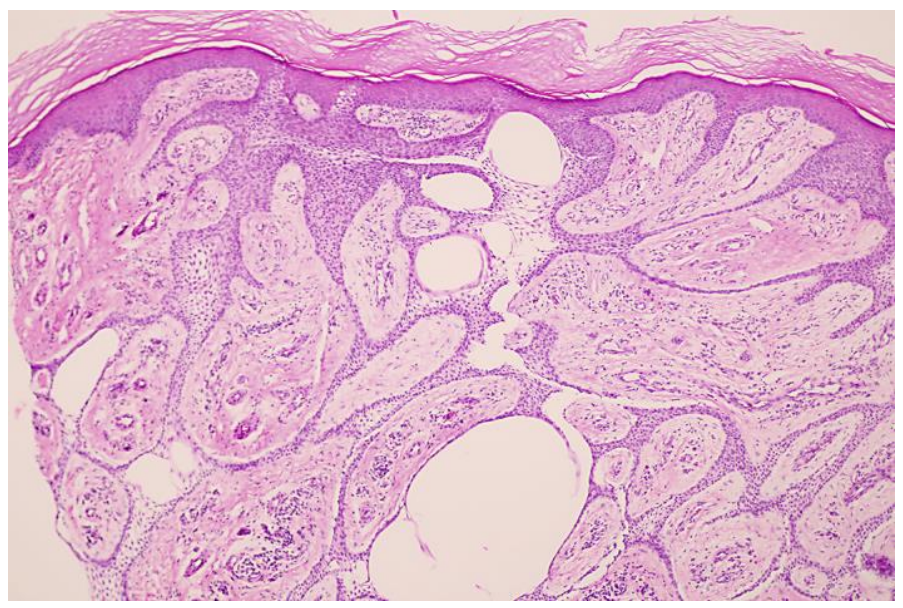

Fig. 3. Histopathological findings demonstrate multiple foci of thin anastomosing strands of uniform cuboidal cells emanating from the epidermis. Hematoxylin-eosin. $\times 40$. 


\section{Case Reports in Dermatology}

Case Rep Dermatol 2016;8:124-129

Sirikham et al:: Reactive Eccrine Syringofibroadenoma Associated with Neuropathy, Venous Stasis, and Diabetic Foot Ulcer

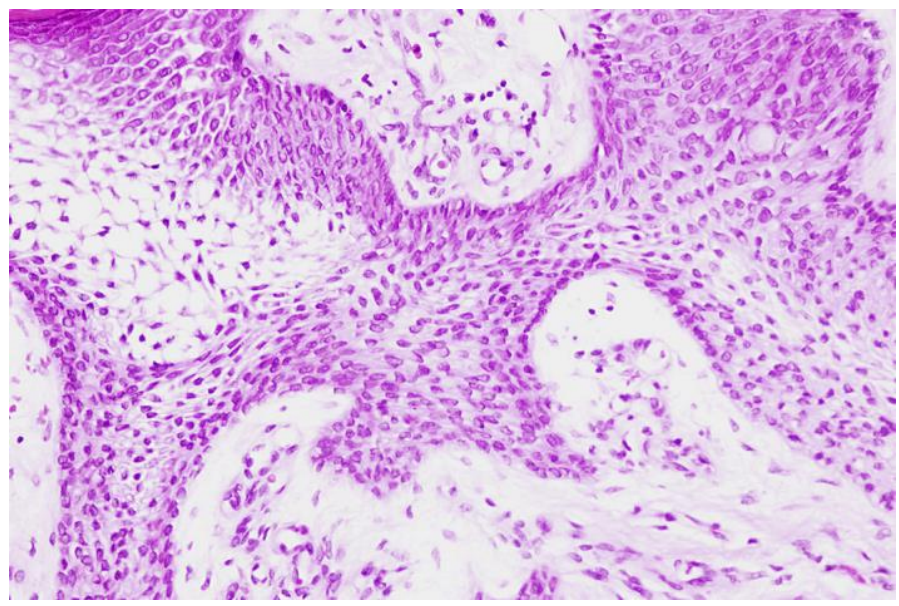

Fig. 4. Epithelial strands show ductal differentiation embedded within the fibrovascular stroma. Hematoxylin-eosin. $\times 400$. 